\title{
A CONVERSAÇÃO E DELIBERAÇÃO NO AMBIENTE NA INTERNET: ESTUDO DA PÁGINA DE FACEBOOK "ME SOLTA AMAPÁ"
}

\author{
CONVERSATION AND DELIBERATION IN THE INTERNET ENVIRONMENT: \\ STUDY OF THE FACEBOOK PAGE “ME SOLTA AMAPÁ”
}

Antonio Carlos Sardinha1
https://orcid.org/0000-0001-5257-3263
$\underline{\text { http://lattes.cnpq.br/8522818562933819 }}$

Érica da Cruz Favacho² https://orcid.org/0000-0002-5939-5073 http://lattes.cnpq.br/4317045299440132

Recebido em 1 de março de 2020

Aprovado em 4 de maio de 2020

\begin{abstract}
RESUMO: A proposta do artigo é analisar a página "Me Solta Amapá", publicada na rede social Facebook, como espaço de conversação on-line, de forma a compreender aproximações ou vestígios de uma arena pré-deliberativa, potencialmente articulada a outras esferas de deliberação, no que entendemos ser a cadeia deliberativa formada de escalas variadas e interdependentes. A pesquisa está inserida em um conjunto de investigações no campo da Comunicação Política que busca observar o espaço da internet (potencialidades e desafios), para o exercício da participação política. A página em análise é um dos espaços virtuais com número de inscritos e curtidas superior ao de meios de comunicação locais e chama a atenção pela adesão dos inscritos e participação nos comentários sobre assuntos e fatos de interesse da comunidade local. Por meio de metodologia sugerida para observar os processos deliberativos on-line (Marques, 2011), procuramos apontar como a conversação na página se aproxima ou apresenta vestígios de uma ambiência deliberativa, bem como atende aos preceitos da conversação no contexto de uma arena de deliberação democrática (Mansbridge, 1999). Como elementos conclusivos, destacamos que, apesar dos níveis de discussão apontarem para aspectos pouco reflexivos, com níveis de argumentação pouco densos e sustentação prioritária em pontos de vistas particulares, a página é vista como espaço de identificação entre os usuários, com níveis de discussão e troca de opinião fortemente associada a questões e demandas locais.
\end{abstract}

Palavras-chave: Teoria democrática. Deliberação Pública. Redes sociais.

\begin{abstract}
The purpose of the article is to analyze the page "Me Solta Amapá", published on the social network Facebook, as a space for online conversation, in order to understand approaches or traces of a pre-deliberative arena, potentially articulated with other spheres of deliberation, in the that we understand to be the deliberative chain

${ }^{1}$ Doutorado em Comunicação (UNESP). Professor no Curso de Especialização em Estudos Culturais e Políticas Públicas/Unifap. Integrante do Grupo de Pesquisa Estudos Interdisciplinares em Cultura e Políticas Públicas e do Grupo de Pesquisa Mídia, Política e Democracia.

${ }^{2}$ Jornalista. Especialista em Estudos Culturais e Políticas Públicas (Unifap). Integrante do Grupo de Pesquisa Estudos Interdisciplinares em Cultura e Políticas Públicas.
\end{abstract}


formed of varied and interdependent scales. The research is part of a set of investigations in the field of Political Communication that seeks to observe the internet space (potential and challenges), for the exercise of political participation. The page under analysis is one of the virtual spaces with a greater number of subscribers and likes than the local media and draws attention by the adhesion of subscribers and participation in comments on issues and facts of interest to the local community. Through the suggested methodology to observe the deliberative processes online (Marques, 2011), we try to point out how the conversation on the page approaches or presents traces of a deliberative ambience, as well as meets the precepts of the conversation in the context of a democratic deliberation arena (Mansbridge, 1999). As conclusive elements, we highlight that, although the levels of discussion point to little reflective aspects, with low levels of argument and priority support in particular points of view, the page is seen as a space for identification between users, with levels of discussion and exchange of opinion strongly associated with local issues and demands.

Keywords: Conversation. Deliberation. Facebook. Me solta Amapá.

\section{APONTAMENTOS GERAIS}

A internet como um território de práticas e processos sociais de natureza particular tem interessado como espaço de investigação para um campo amplo e interdisciplinar de estudos. O campo da Comunicação Política tem observado, dentre outros aspectos, as dimensões, possibilidades e desafios da ação política, a partir da apropriação pelos sujeitos (institucionalizados ou não) dos dispositivos disponibilizados pelas tecnologias da informação e da comunicação (TICs).

Considerando esse contexto, o presente artigo trata da conversação no contexto deliberativo (MANSBRIDGE, 1999; MARQUES, 2011; MAIA 2008) na interface com o ambiente online, por meio do estudo da página "Me solta Amapá", no Facebook. A proposta central foi observar como se dá a conversação a partir das ferramentas disponíveis pela rede social, considerando a abrangência e participação de usuários nesse espaço digital. A título de ilustração, até meados de junho de 2019 era seguido por 63.453 outros perfis, com um total de 59.271 curtidas, superando páginas oficiais de veículos jornalísticos do Amapá (TV Amapá, afiliada da Rede Globo que inclui o portal de notícias G1AP, chegava a 42.064 curtidas e 41.725 seguidores no período indicado).

Essa característica da página, bem como a participação dos internautas, chama a atenção para a importância desse espaço virtual na formatação de uma esfera de discussão sobre questões locais, relacionadas ao cotidiano da cidade: denúncias sobre falta de serviços, divulgação de campanhas de arrecadação de fundos para populares, difusão de notícias sobre a vida política e social do Amapá.

O que destacamos é que a página, para além de um espaço de divulgação e difusão de conteúdos informativos (não necessariamente jornalísticos), torna-se um espaço de troca de opiniões, baseadas em impressões muito particulares, intencionais, baseadas em uma perspectiva particular, sem a base argumentativa construída a partir do uso da razão, nos moldes habermasianos (HABERMAS, 1997) como elementos centrais para caracterizar a deliberação. No entanto, a conversação produzida é um instrumento importante para caracterizar a página como uma arena pré-deliberativa, que inserida em uma ambiência deliberativa mais ampla, assume um papel de tematizar e problematizar questões de interesse público, que podem 
ocupar o centro de espaços de deliberação formais e/ou institucionais.

O que chamamos a atenção é para a importância da conversação nesse contexto deliberativo mais amplo, mas não só. É importante compreender como os espaços de conversação são constituídos em redes sociais, mesmo sob as restrições e limitações para a comunicação nesses ambientes on-line, inserindo-se nessa perspectiva como arenas legítimas (embora desconsideradas) de manifestação e participação cidadã mais interessantes que outras esferas de participação locais.

Por certo, as facilidades e comodidades das ferramentas tecnológicas são fatores de ordem sociotécnica que poderiam justificar, de imediato, esse indício de envolvimento despretensioso de cidadãos em assuntos da vida pública. Mas para, além disso, as motivações que despertam interesse de cidadãos em uma página, que materializa no ambiente da internet a conversação cotidiana, requerem uma mirada mais abrangente para captar as possibilidades de participação no debate público. Mesmo funcionando sem apresentar resultados concretos do ponto de vista deliberativo, esses espaços podem assumir uma funcionalidade em contextos deliberativos alargados na contemporaneidade pelas possibilidades tecnológicas.

Conceitualmente, entendemos a conversação como uma prática comunicativa distinta da deliberação pelo uso da linguagem e finalidade. Em síntese, a conversação não exige dos participantes uma postura reflexiva dos recursos linguísticos de forma a construir argumentos racionais que procurem gerar decisões consensuadas, a partir dessa ação comunicativa específica.

De acordo com Marques e Martino (2016), Habermas já apontava essa diferença entre deliberação e conversação, tratando essa última como prática comunicativa mais incipiente, distante do nível de complexidade observado em uma ação comunicativa orientada para deliberação, mas com um "grau de problematização implícito ou latente" (MARQUES; MARTINO, 2016, p.05). Ainda com base nos autores, é importante destacar que a conversação cívica, como uma comunicação de natureza mais informal, sem a pretensão de produzir deliberação, ao surgir em contextos informais, são importantes pela possibilidade de aproximar sujeitos, criar laços e pertencimento.

Ao mesmo tempo, a conversação tem um importante papel ao criar possibilidades de que os sujeitos revisem perspectivas, exercitem capacidade crítica para pensar, problematizar e perceber para além de sua perspectiva individual, aspectos da realidade cotidiana que, podem ser ou já estão sendo tematizados em uma dada arena deliberativa. É como se a conversação se tornasse um espaço preparatório para a inserção dos indivíduos em uma cadeia deliberativa formada por outros espaços. Isso porque a atividade deliberativa está inserida no que Mansbridge (1999) chama de "arena de deliberação democrática", com configuração complexa envolvendo múltiplas ideias, atores e instâncias de deliberação. Nessa arena, o que compartilhamos com a autora é que "quando novas ideias se difundem na sociedade mais ampla, diferentes tipos de pessoas as apreendem e as testam por diferentes razões” (MANSBRIDGE, 1999, p. 219). O que exigirá níveis distintos de tratamento e relações comunicativas até uma situação próxima do ideal deliberativo, capazes de incorporar limitações e potencialidades que são próprias de cada camada que acaba formatando essa arena ampla e multiforme para deliberação.

De acordo com Marques e Maia, a conversação cotidiana tem um papel importante nesse processo deliberativo: 
A conversação cotidiana, ao proporcionar oportunidades para que as pessoas explicitem, negociem e justifiquem suas necessidades e projetos, pode auxiliá-las a entender melhor o que querem e o que precisam, individual e coletivamente. O contexto comunicativo formado por meio dessa conversação é geralmente marcado pela afirmação e renovação de quadros compartilhados de valores, incluindo, também, é claro, a reprodução de preconceitos e desigualdades (MARQUES; MAIA, 2008, p. 147).

Esse enquadramento conceitual é importante para, de imediato, posicionar nossa leitura para a realidade empírica analisada. A página da rede social Facebook "Me solta Amapá" tem um nível de conversação caracterizada por esse pouco rigor no uso (reflexivo) da linguagem e, sem pretensão de se inserir ou se definir como um espaço deliberativo. No entanto, os participantes assumem a página como um local onde podem se expressar livremente para 'os seus', opinando sem rigor analítico/argumentativo, muitas vezes, baseados em impressões particulares, potencializado por posturas subjetivas, com viés emotivo, envolvendo fatos publicados que, por sua vez, ressaltam problemáticas sensíveis da realidade local. São características que não tira a importância da página, pela capacidade agregativa e de participação, como espaço de pré-agendamento de demandas, ou de problematização que, mesmo sob um nível particular, possibilita por meio da interação um processo pedagógico de ampliação de perspectivas ou refinamento da opinião para uso em outros contextos.

Partindo dessa perspectiva, a questão-problema que nos instiga é saber o quão próximo da deliberação está esse espaço de conversação local na internet, com expressiva reunião de usuários.

O tratamento empírico dos dados adota recursos metodológicos indicados por Marques (2011) para observar a discussão política e deliberativa nos espaços on-line, a partir de cinco princípios: discussão crítico-racional, reciprocidade, reflexividade, igualdade discursiva e liberdade discursiva.

A proposta é buscar a caracterização da conversação que acontece no contexto da página virtual "Me solta Amapá", de forma a compreender aproximações ou vestígios de uma arena pré-deliberativa, potencialmente articulada a outras esferas de deliberação, no que entendemos ser a cadeia deliberativa formada de escalas variadas e interdependentes (com outros fóruns, esferas e espaços institucionais de deliberação).

Para operacionalizar isso, recorre-se à análise de conteúdo das mensagens selecionadas em um espaço temporal, considerando a narrativa que se delineia; afirmações e respostas dos participantes; as justificativas; as formas de articulação; os turnos de fala; os fios de discussão estabelecidos; e a complexidade presente na conversação.

Considerando a limitação do artigo, selecionamos três postagens que mobilizaram um maior número de inscritos na página durante o período de pesquisa (junho de 2018 a junho de 2019) para observar o que era o objetivo da nossa proposta: caracterizar a conversação online na página do Facebook "Me Solta Amapá” e verificar potencialidades deliberativas desse espaço, considerando sua peculiaridade como arena de conversação.

\section{ANÁLISE DE DADOS}

A observação da página iniciou em 15 de junho de 2018 e se encerrou em 23 de junho de 2019. Neste período, percebeu-se que ela funciona como um espaço propagador de informações diversas, que vão desde reclamações sobre serviços públicos que não funcionam, 
campanhas de mobilização para ajudar pessoas a acharem objetos perdidos ou receberem doações (de sangue, inclusive).

Além disso, na página foi possível observar notícias compartilhadas de outros canais, denúncias de crimes por meio do compartilhamento de fotos e vídeos extraídos de circuito interno de segurança de estabelecimento comerciais vítimas de assaltos, imagens e vídeos de acidentes em via pública, até prisões realizadas pelas polícias militar e civil, etc.

Figura 1: Reprodução do Facebook de uma postagem realizada no dia 15 de junho de 2018.

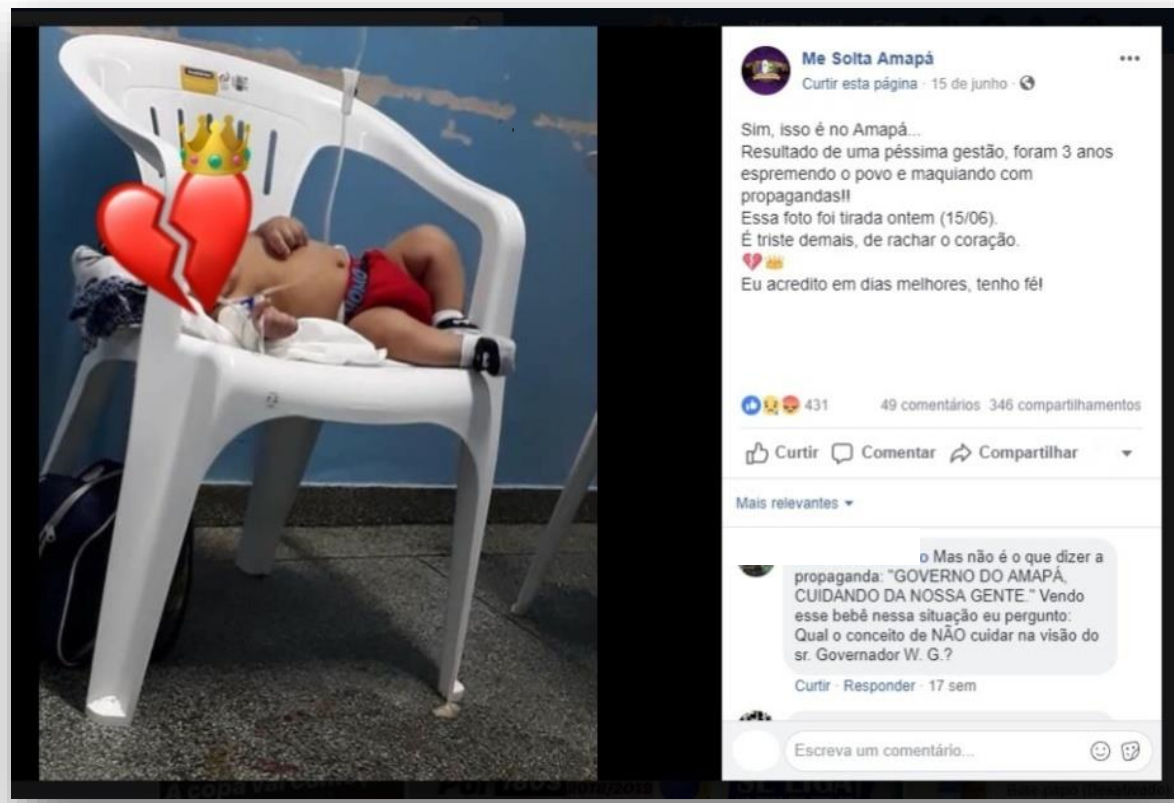

Figura 2: Reprodução do Facebook de uma postagem realizada no dia 12 de julho de 2018.

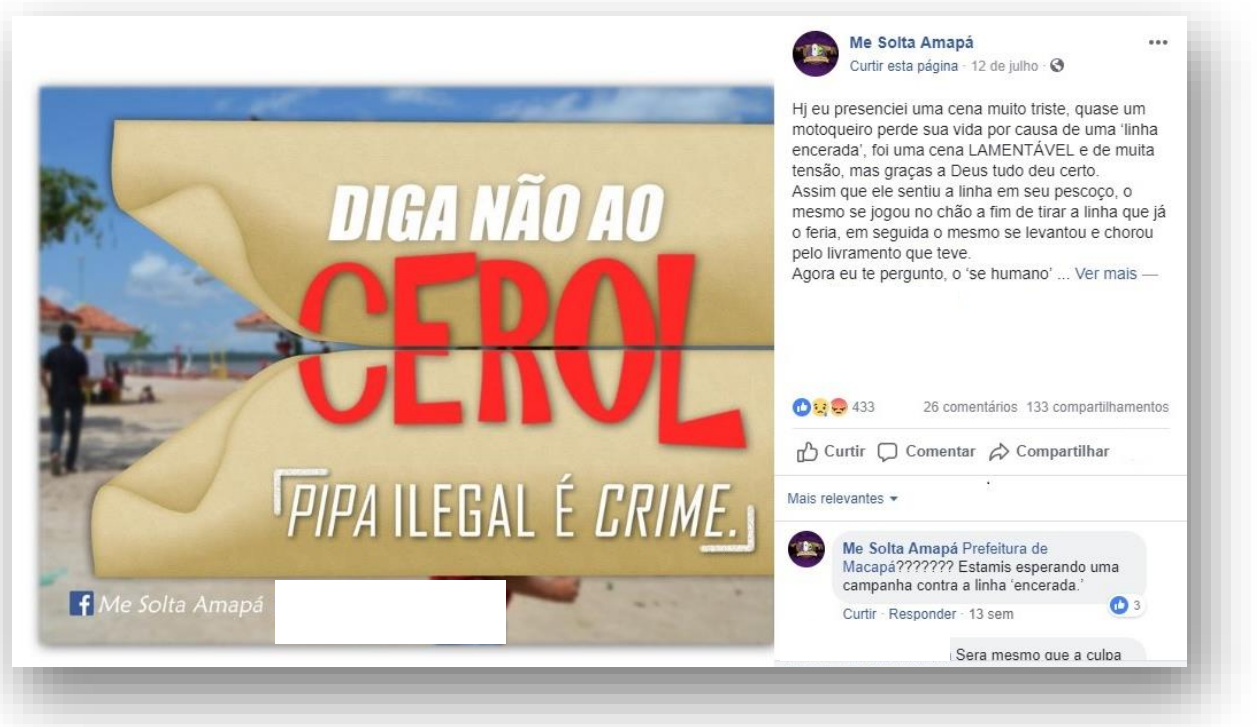

PRACS: Revista Eletrônica de Humanidades do Curso de Ciências Sociais da UNIFAP 
Figura 3: Reprodução do Facebook de uma postagem realizada no dia 3 de setembro de 2018.

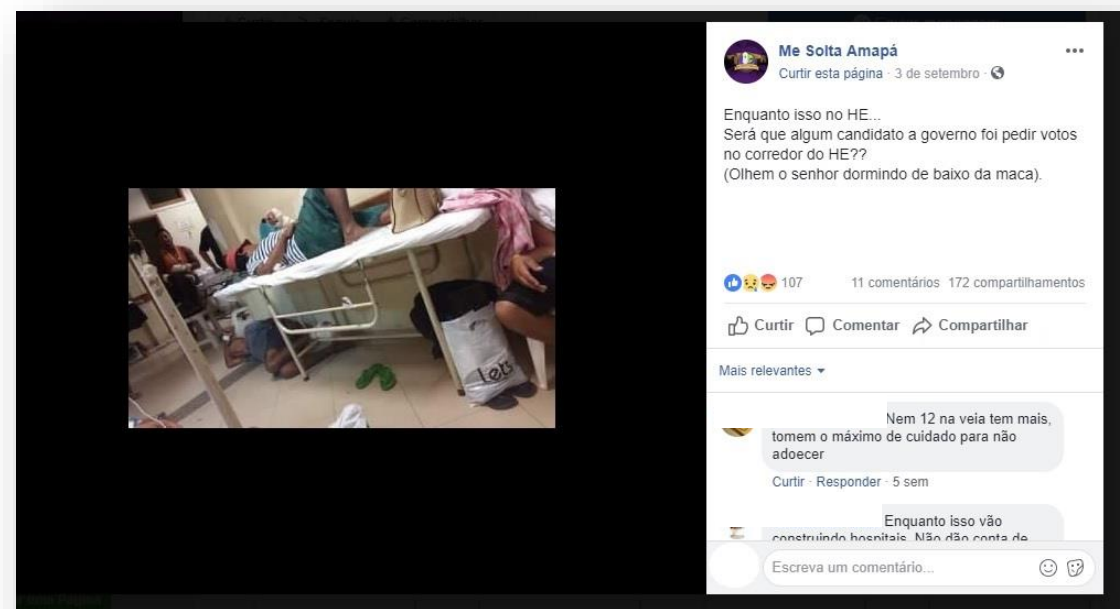

Para iniciar o diagnóstico, toma-se como subsídio para apresentação de notas, o exemplo apresentado a seguir, quando se observa a postagem datada de 20 de junho de 2019 de uma notícia publicada, inicialmente em 2014, no site do Senado sobre a manifestação do Senador - pelo PSOL-AP na época - Randolfe Rodrigues, em que defendia a necessidade de um novo modelo de segurança pública e atuação da polícia no país.

Figura 4: Reprodução do Facebook de uma postagem realizada no dia 20 de junho de 2019.

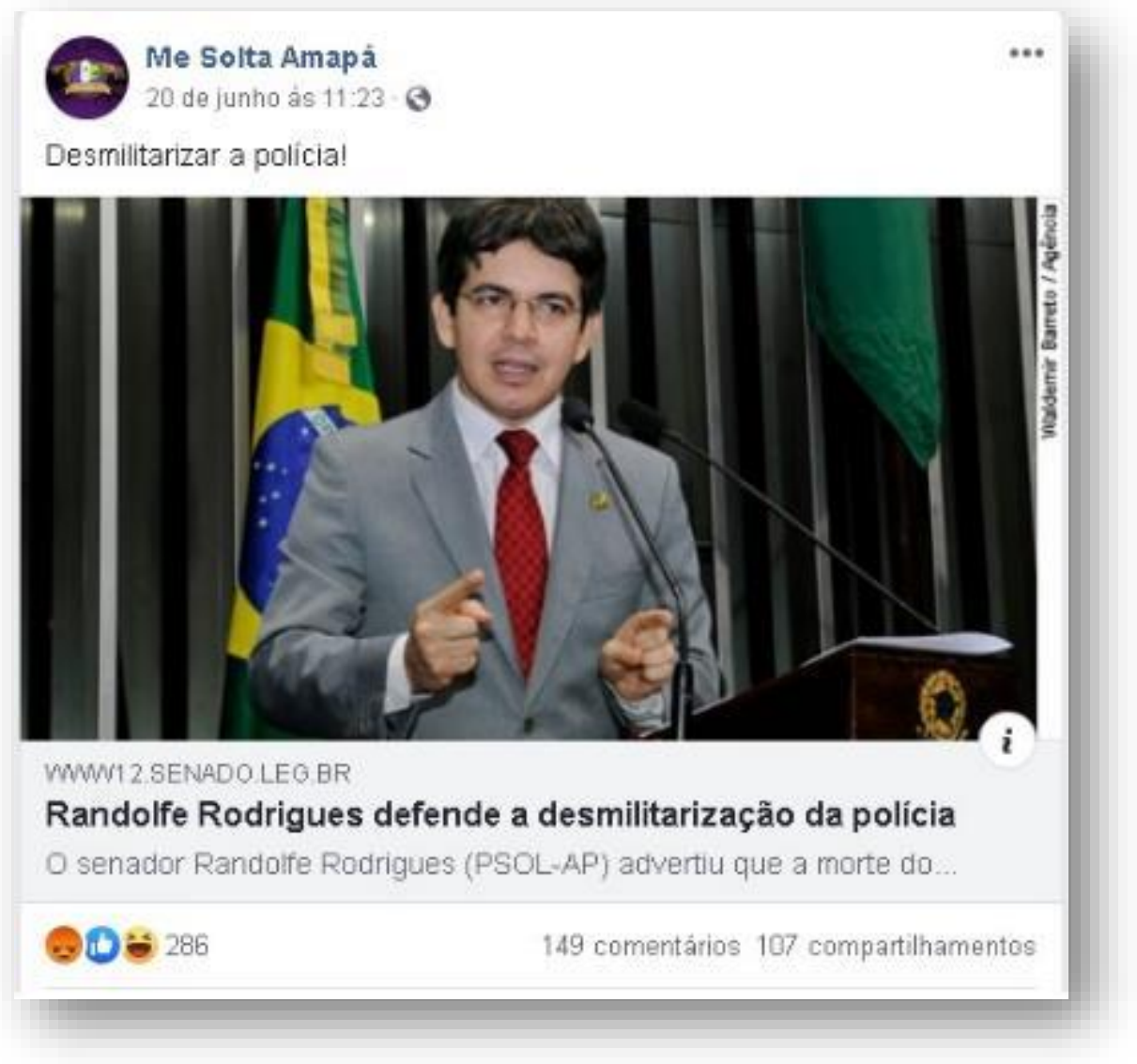

PRACS: Revista Eletrônica de Humanidades do Curso de Ciências Sociais da UNIFAP 
A publicação atraiu - até a data em que foi tomada para registro - 149 comentários e 107 compartilhamentos, sem contar as 286 reações. Dessas participações foram selecionados exemplos de interações que ampliaram o debate e que geraram reciprocidade (ver figura 5).

Figura 5: Reprodução do Facebook.

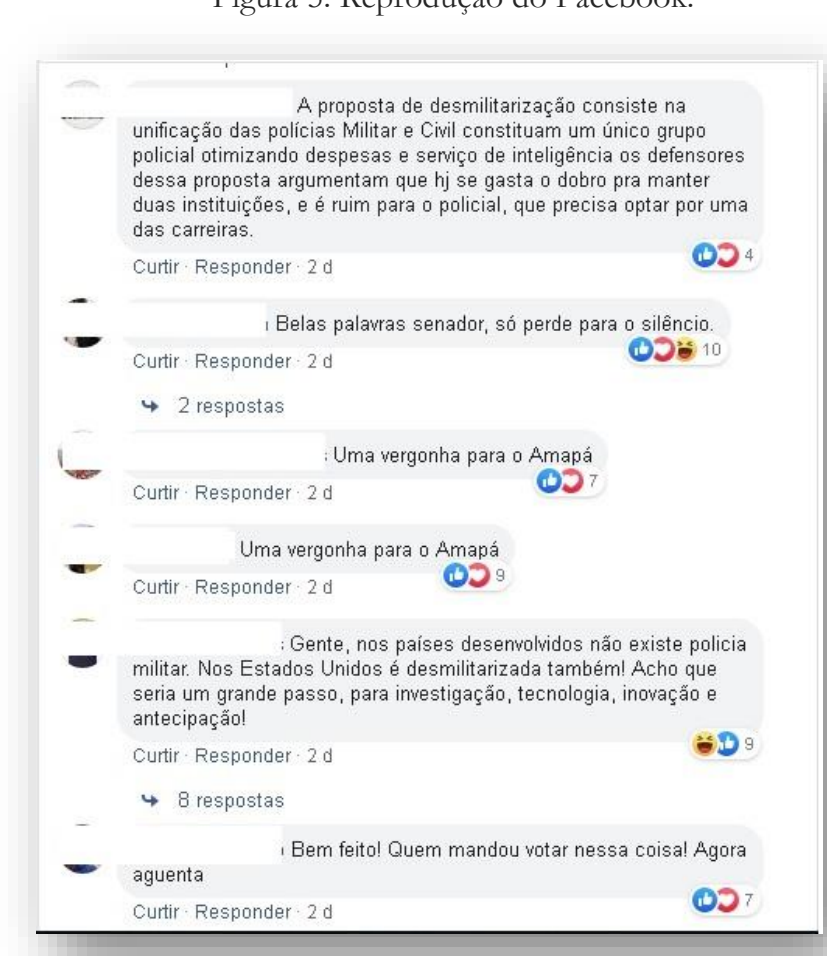

Note-se que, neste recorte selecionado, entre os 149 comentários, um causou repercussão por meio de oito respostas de seis pessoas diferentes, apresentadas na figura 6. Desse escopo de análise percebe-se que há discussão crítico-racional porque o número de comentários aumentou na medida em que os participantes sentiram maior necessidade de justificar seus pontos de vista. Também se tornou perceptível a presença de reciprocidade, a partir da observação da alternância de turnos de fala, mas uma baixa reflexividade, uma vez que o teor crítico dos interlocutores tornou-se agudo, de maneira pouco flexível para alterar suas opiniões.

É possível perceber que a discussão foi realizada por meio de argumentos de pessoas que apoiavam a ideia, que se preocuparam em esclarecer conceitualmente o que significa a desmilitarização com o intuito de mostrar porque a proposta seria plausível ou baseando-se em alegações de que o modelo já é adotado em outros países e que, por isso, o Brasil poderia aderir; e outras que criticavam o posicionamento do senador, mas com poucas justificativas. Nesse último caso, está a indicação que a crítica parte de perspectivas pessoais, afetivas, de empatia, que acabam permeando o debate. 
Figura 6: Reprodução do Facebook.

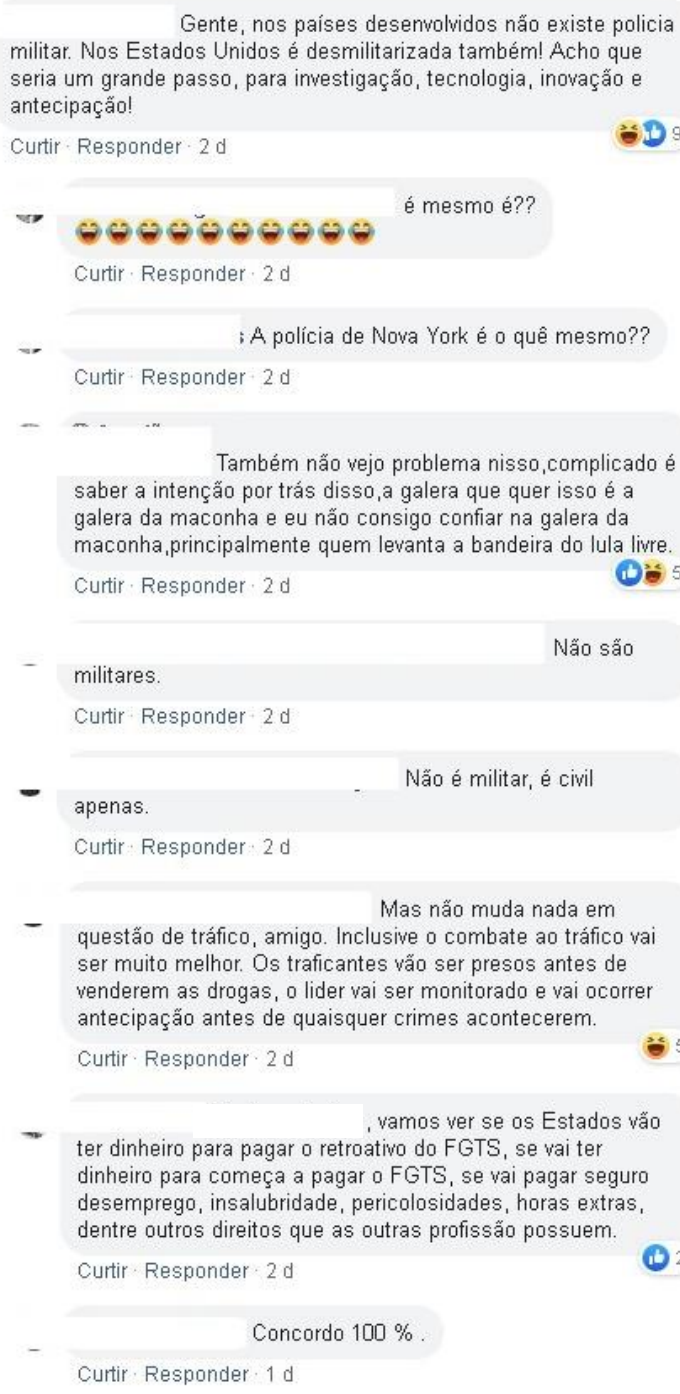

Deste fragmento também se observou que os participantes puderam manifestar seus discursos em pé de igualdade, sem a presença de um moderador que vetasse de alguma maneira o que era posto nos comentários. Do mesmo modo, outros interlocutores não se manifestaram como limitadores de falas. Isso, automaticamente nos leva à análise do quinto critério: a liberdade discursiva. Percebe-se que, apesar de a rede social Facebook possuir a funcionalidade de bloqueio de comentários, os participantes manifestam-se livremente, expondo opiniões favoráveis e contrárias, com a possibilidade de fazer trocas discursivas uns com os outros.

Outro exemplo em que há liberdade discursiva pode ser verificado na postagem retratada na figura 1 (acima), em que o administrador da página expõe a foto de uma criança recebendo cuidados médicos em uma cadeira, com a legenda: "Sim, isso é o Amapá... Resultado de uma péssima gestão, foram 3 anos espremendo o povo e maquiando com propagandas!! Essa foto foi tirada ontem (15/06). É triste demais, de rachar o coração. Eu acredito em dias melhores, tenho fé!". 
Ela obteve 49 comentários e 346 compartilhamentos. Entre as manifestações registradas no recorte feito, destaco algumas na figura 7.

Nesse caso é interessante perceber que o administrador da página também faz comentários de seu perfil pessoal (por isso não foi suprimida a identidade do usuário), e dessa expressão de opinião nota-se um teor crítico em relação à gestão política que governa o estado. Sobre isso é importante salientar que o tema político estava em maior destaque na página por conta do período eleitoral que se aproximava e, nesse contexto, é perceptível o interesse do administrador em tratar de nomes de figuras que seriam candidatas nas eleições que se aproximavam. No entanto, em se tratando de liberdade discursiva, vê-se que não há a ação de moderação no sentido de constranger as interações, pelo contrário, o personagem dialoga com as pessoas que também comentam.

Figura 7: Reprodução do Facebook.

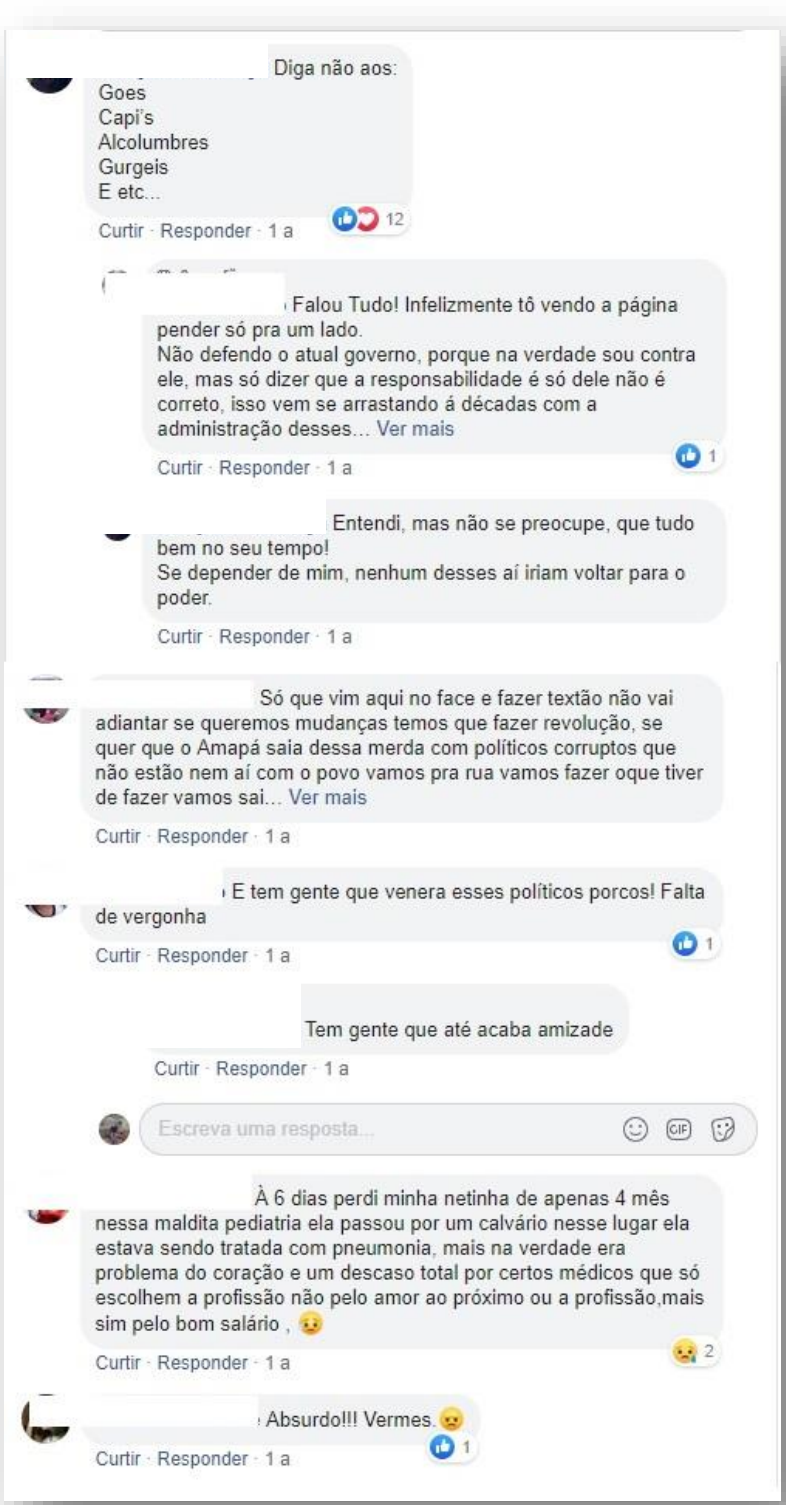

Em relação aos outros critérios, esse trecho destacado revela a existência de discussão crítico-racional (pela presença de comentários com teor de avaliação baseado em aspectos e fatos 
concretos da realidade experienciada pelo usuário) quando analisamos nos comentários que a narrativa que se delineia é no sentido de criticar o posicionamento do administrador, quando os seguidores comentam e demonstram descontentamento quanto ao modo de governar de outros gestores. Nota-se que as afirmações e respostas dos indivíduos situam-se nestas duas frentes: crítica à postagem e apoio ao conteúdo veiculado. As justificativas apresentadas corroboram com isso, ora dizendo que o autor da postagem pende somente para um lado quando critica os problemas do estado, ora citando exemplos que acompanham a mesma linha de raciocínio, ou seja, apontando outras situações problemáticas da saúde do estado.

Os fios de discussão acontecem por meio da troca de argumentos, ainda incipientes baseados em percepções particulares vivenciadas pelo próprio usuário ou pessoas próximas, com turnos de fala bem delimitados. O que nos mostra a existência do critério da reciprocidade. Isto é, os usuários que participam daquela interação conseguem se manifestar e dialogar com o outro, por meio da alternância de momentos de expressão, sem haver centralização de nenhuma parte. Pelo turno de comentários é possível indicar uma disposição aos comentários entre os participantes, mesmo em situações de discordância.

No entanto, em relação à reflexividade não se percebe participantes propensos a serem flexíveis a ponto de considerar as divergências, alterar suas opiniões e preferências quando confrontados com críticas ou com argumentos sustentados pelos outros, principalmente se tomarmos como frente de análise o autor inicial da postagem. Ele recebeu críticas, mas não demonstrou estar disposto a mudar de posicionamento ("Entendi, mas não se preocupe, que tudo bem (sic) ao seu tempo!’”).

Por outro lado, a igualdade discursiva pode ser observada na troca conversacional em análise. Vê-se que os personagens que interagiram no momento tiveram iguais oportunidades de fazer afirmações e questionamentos e de expressar necessidades e desejos.

A próxima postagem (figura 8) relaciona especificamente a dinâmica de conversação baseada em assuntos apresentados de um modo particular, mas com dimensão pública por estar vinculado a problemas estruturais que as percepções seletivas dos usuários não conseguem necessariamente enquadrar criticamente no contexto de uma problemática ampla e de interesse público, como é o tema de crianças desaparecidas e políticas públicas para enfrentamento da problemática.

Antes, é importante destacar que mesmo postagens que problematizam aspectos de assuntos ou agendas públicas, já em debate em outra esfera pública (a midiática, por exemplo), não se nota uma dinâmica conversacional densa que se aproxime das características deliberativas ideais. Mesmo existindo clima de interação que sugere debates entre os participantes, a troca de ideias (embrionárias e pontuais) e argumentos (baseados em percepções e experiências) instituem uma relação em que pontos de vistas parecidos são apoiados/reforçados e os distintos/negados. Ou seja, não se toca na essência do que é apresentado com contrapontos fundamentados em fatos ou informações mais amplas capazes de contextualizar o que é dito, mas se contesta pela busca de estratégias mais simplista (porque vota ou é do grupo político, pela amizade ou confiança, etc.).

Para exemplificar postagens de conteúdos mais pessoais, que geraram discussões mais triviais, destaca-se a figura 8 . Trata-se de um apelo de busca de uma criança desaparecida. O post é de 19 de junho de 2019 e até a data da análise tinha atraído 122 comentários e 1,9 mil compartilhamentos. Note-se que, nesse tipo de conteúdo, o número de compartilhamentos cresce e é bem alto se comparado ao número de comentários por conta do envolvimento que gera, 
uma vez que há o interesse em colaborar com a procura por meio da ampliação e propagação daquele material.

Figura 8: Reprodução do Facebook.

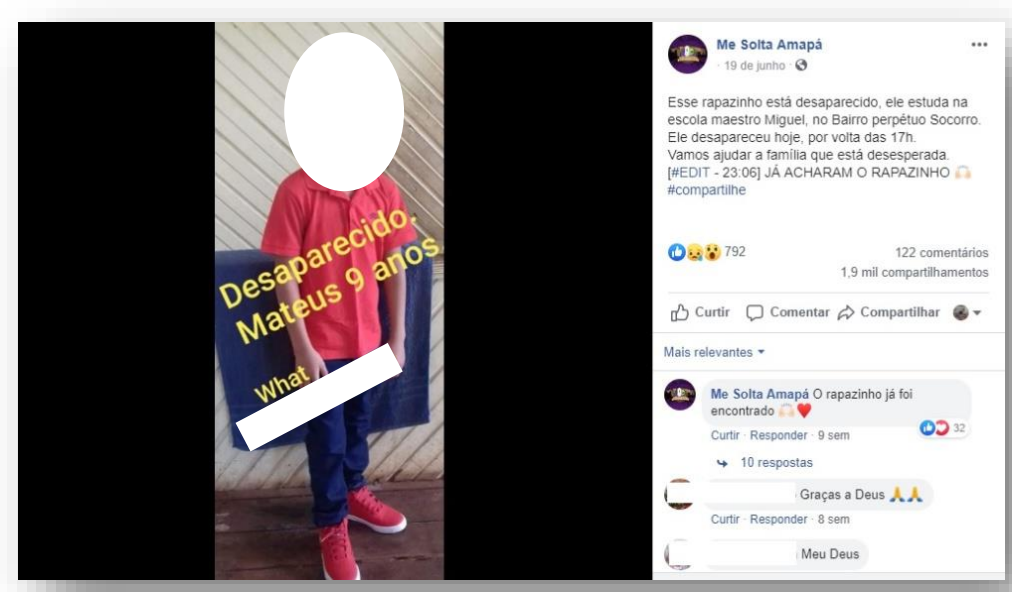

Figura 9: Reprodução do Facebook.

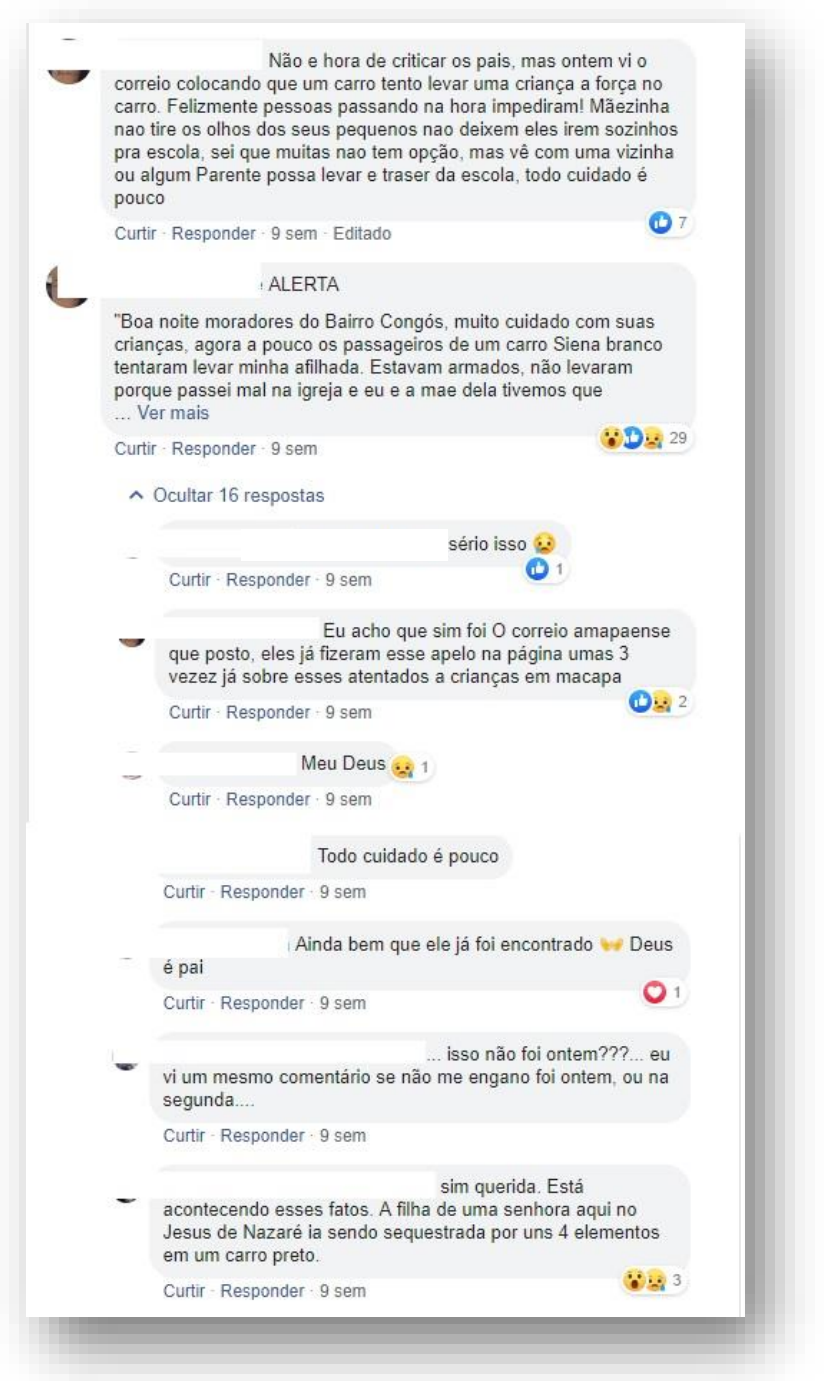

PRACS: Revista Eletrônica de Humanidades do Curso de Ciências Sociais da UNIFAP 
Aponta-se que a postagem, dado o seu conteúdo peculiar, atrai comentários de pessoas que se compadecem com o acontecimento e que se manifestam neste sentido, mas também há aqueles usuários que usam do ocorrido para fazer alertas de cuidados gerais para que outras situações de desaparecimento não aconteçam (Figura 9). De modo particular, um perfil relata um perigo e aproveita o momento para advertir os pais sobre casos semelhantes que estão acontecendo na cidade. Não se sabe se o fato é verídico, mas logo se vê que o conteúdo provoca aceitação entre os outros, que acreditam ser verdade.

Analisar postagens e comentários como do exemplo acima é importante porque nos ajuda a pensar a conversação sobre agendas mais localizadas. Isso mostra a perspectiva tratada por Marques e Martino (2016), quando citam, a partir de Habermas, que a conversação ocupa um nível mais ligado à "prática comunicativa ingênua". Ou seja, nos auxilia na compreensão de que essa dinâmica ligada ao mundo privado, mais intimista, é um modo de pensar as possibilidades da conversação como arena pré-deliberativa, ao conferir grande importância aos aspectos estabelecidos nos contextos rotineiros, pois é nessas circunstâncias que percebemos a importância social para problemas comuns. Além disso, essa dimensão da conversação reforça vínculos de solidariedade e de pertencimento, que são fundamentais em um ambiente em que os sujeitos ensaiam e aprendem a conviver publicamente em um contexto de debate e manifestação de opiniões.

Retomando o que diz Marques e Maia (2008), a partir do momento que a conversação cotidiana proporciona oportunidades às pessoas para que explicitem negociem e justifiquem suas necessidades, ela é capaz de auxiliá-las no entendimento do que querem e precisam, individual e coletivamente.

\section{CONSIDERAÇÕES FINAIS}

Como elementos conclusivos, destacamos que, apesar dos níveis de discussão apontarem para aspectos pouco reflexivos, com níveis de argumentação pouco densos, com sustentação baseada em impressões particulares, a página no Facebook "Me solta Amapá” é vista como espaço de identificação entre os usuários, com níveis de discussão e troca de opinião com forte relação com as questões e demandas locais. Esse aspecto por si só é importante, considerando essa perspectiva pré-deliberativa em torno da conversação, por reunir, tematizar e mobilizar usuários em um espaço de encontro e trocas sobre questões de interesse comum.

A identificação da página como um exemplo de como a conversação cotidiana, levada aos espaços das redes sociais, remete considerar a presença de conversação do tipo on-line que cumpre o papel que essa prática comunicativa assume em uma cadeia complexa de deliberação nas democracias contemporâneas. O primeiro papel é a possibilidade de a página servir como um meio para e não um fim em si mesmo, quando observamos a deliberação como resultado de um processo de uso reflexivo da linguagem e pela demanda por ação comunicativa orientada para o entendimento.

Nesse caso, a conversação on-line identificada na página assume um aspecto pedagógico, no sentido de servir como um espaço de experimentação em torno da experiência de um usuário em assumir publicamente pontos de vistas, apresentá-lo e, por consequência, lidar com a aceitação e desaprovação (curtidas) dos seus pares naquele espaço de interação. Ao mesmo tempo, pode incorporar aprendizados sobre questões em discussão, mesmo que buscando lidar apenas com as opiniões e pontos de vistas parecidos, é possível surgir novas leituras ou ampliação do 
quadro de referência do participante em relação ao que já vinha pensando.

Lidar com as divergências, mesmo que desconsideradas por motivações pessoalizadas e particularistas, pode mobilizar o usuário a sair de uma zona de conforto no que se refere à forma como elabora sua opinião e perspectivas sobre questões comuns. Pedagogicamente, isso é válido para indicar a necessidade de lidar com o contraditório como parte de uma exposição pública de ideias, mesmo que essa compreensão seja incipiente nas postagens no interior da página. Além disso, a forte presença de temas e questões locais tomando a atenção dos usuários aponta para uma capacidade da página em se apresentar como uma arena capaz (se não de discutir) de agendar questões de interesse geral, que estão fortemente ligadas à realidade local, instituindo uma demanda por falar e tratar de problemas que afetam a comunidade.

Esses aspectos poderiam ser aprofundados com abordagens qualitativas sobre um conjunto de postagens de um grupo de usuários de modo pormenorizado. No entanto, para efeitos de escopo que está em identificar na realidade empírica presença de questões e aspectos conceituais, a observação da página nos indica um movimento de aprendizado que espaços on-line para conversação podem assumir para a deliberação, bem como os desafios comunicacionais, cognitivos e procedimentais necessários para o exercício da deliberação.

\section{REFERÊNCIAS}

HABERMAS, Jürgen. Direito e Democracia. Vol. II. Rio de Janeiro: Tempo Brasileiro, 1997.

MANSBRIDGE, Jane. A conversação cotidiana no sistema deliberativo. In: MARQUES, A. C. S (org). A deliberação pública e suas dimensões sociais, políticas e comunicativas: textos fundamentais. Belo Horizonte: Autêntica Editora, p. 207-237, 1999.

MARQUES, Ângela Cristina Salgueiro. Aspectos teórico-metodológicos do processo comunicativo de deliberação online. Revista Brasileira de Ciência Política, n. 6, Brasília, p. 1940, 2011.

; MARTINO, Luís Mauro Sá. A politização da conversação cotidiana e suas relações com processos deliberativos. In $10^{\circ}$ Encontro da Associação Brasileira de Ciência Política, 2016. Belo Horizonte. Anais. Belo Horizonte, Associação Brasileira de Ciência Política, 2006.

; MAIA, Rousiley Celi Moreira. A conversação sobre temas políticos em contextos comunicativos do cotidiano. Política e Sociedade, n. 12, Florianópolis, p. 143-175, 2008. 